\title{
Efeito do consumo de erva-mate (Ilex paraguariensis) sobre o ganho de peso e a glicemia de jejum em ratos alimentados com uma dieta hiperlipídica
}

\author{
Effect of yerba mate (Ilex paraguariensis) consumption on weight gain and fasting \\ glucose in rats fed with a high-fat diet
}

\begin{abstract}
Alisson Diego Machado ${ }^{1}$, Marcella Cristina de Souza Silva ${ }^{2}$, João Paulo Campos Pesci ${ }^{1}$, Camila Alkalay Helber ${ }^{1}$, Fernanda Presbítero de Albuquerque Dainez ${ }^{1}$, Larissa Aguiar Silva $^{3}$, Eder de Carvalho Pincinato ${ }^{4}$, Isabela Rosier Olimpio Pereira ${ }^{5}$
\end{abstract}

\section{RESUMO}

Objetivo: Avaliar o efeito do consumo de erva-mate sobre o ganho de peso e a glicemia de jejum em ratos alimentados com uma dieta hiperlipídica.

Materiais e Métodos: Foram utilizados 14 ratos divididos em três grupos. O primeiro grupo $(n=4)$ foi alimentado com ração comercial para ratos, o segundo $(n=5)$ recebeu dieta hiperlipídica e o terceiro $(n=5)$ foi alimentado com dieta hiperlipídica acrescida de infusão de erva-mate, durante 24 dias. Durante o estudo foram monitorados o peso e o índice de Lee e ao final a glicemia de jejum.

Resultados: Os ratos alimentados com dieta hiperlipídica contendo infusão de erva-mate apresentaram menor ganho de peso em relação aos que consumiram apenas a ração hiperlipídica, nos três períodos experimentais analisados ( $p=0,048, p=0,016$ e $p=0,048$, respectivamente). Não houve diferença significativa em relação ao índice de Lee entre os grupos. O consumo da erva-mate promoveu tendência a menores níveis de glicemia de jejum em relação ao grupo alimentado com dieta comercial $(p=0,056)$ e ao grupo que recebeu dieta hiperlipídica $(p=0,075)$.

Conclusão: $O$ consumo de erva-mate proporcionou menor ganho de peso em relação aos ratos que foram alimentados apenas com ração hiperlipídica e tendência a menores níveis de glicemia de jejum.

Palavras-chave: Ilex paraguariensis; hiperlipidemias; ganho de peso; glicemia.

\section{ABSTRACT}

Objective: To evaluate the effect of yerba mate consumption on weight gain and fasting glucose in rats fed with a highfat diet.

Materials and Methods: 14 rats were divided into three groups. The first group $(n=4)$ was fed with standard diet for rats, the second group $(n=5)$ was fed with high-fat diet and the third group $(n=5)$ was fed with high-fat diet added of yerba mate infusion, for 24 days. During the study were monitored the weight and the Lee index. Fasting glucose was measured in the end.

Results: The rats fed a high-fat diet added of infusion of yerba mate showed lower weight gain compared to rats fed only high-fat diet in the three experimental periods analyzed ( $p=0.048, p=0.016$ and $p=0.048$, respectively). There was no significant difference regarding the Lee index between the groups. The consumption of yerba mate promoted tendency to lower levels of fasting glucose compared to rats fed with standard diet $(p=0.056)$ and rats fed a high-fat diet $(p=0.075)$.

Conclusion: The consumption of yerba mate promoted lower weight gain compared to rats that were fed only high-fat diet and a tendency for lower levels of fasting glucose.

Keywords: Ilex paraguariensis; hyperlipidemias; weight gain; blood glucose.

\footnotetext{
${ }^{1}$ Discente do curso de Nutrição da Universidade Presbiteriana Mackenzie.

${ }^{2}$ Nutricionista graduada pela Universidade Presbiteriana Mackenzie.

${ }^{3}$ Nutricionista. Mestranda em Distúrbios do Desenvolvimento pela Universidade Presbiteriana Mackenzie.

${ }^{4}$ Farmacêutico-bioquímico. Doutorando em Clínica Médica pela Universidade Estadual de Campinas. Docente do curso de Farmácia da Universidade Presbiteriana Mackenzie.

${ }^{5}$ Farmacêutica. Doutora em Ciência dos Alimentos pela Universidade de São Paulo. Docente dos cursos de Nutrição, Farmácia e Tecnologia em Gastronomia da Universidade Presbiteriana Mackenzie.
} 


\section{INTRODUÇÃO}

As doenças cardiovasculares representam a principal causa de mortalidade no mundo, sendo que em 2008 aproximadamente 17 milhões de óbitos foram decorrentes das mesmas. O processo de doença mais conhecido nos vasos sanguíneos, que resulta em doenças coronarianas e cerebrovasculares, é a aterosclerose, caracterizada pela deposição de material lipídico nas paredes das artérias, sendo os principais riscos metabólicos para o desenvolvimento da mesma são a hipertensão, o aumento dos níveis séricos de triglicérides e colesterol, a hiperglicemia e o excesso de peso ${ }^{1}$.

Dentre as medidas preventivas destacam-se a diminuição da ingestão de ácidos graxos saturados e o aumento do consumo de fibras. Além dessas ações, inclui-se a ingestão de antioxidantes, que previnem a aterosclerose por inibirem a oxidação das lipoproteínas ricas em colesterol de baixa densidade (LDL-colesterol), diminuindo sua aterogenicidade ${ }^{2}$.

A erva-mate (Ilex paraguariensis) é consumida amplamente na América do Sul e é considerada uma fonte importante de polifenóis, que podem desempenhar papel antioxidante ${ }^{3}$. O consumo dessa erva pode atuar como um efetivo meio de proteção contra danos ao DNA, prevenindo a carcinogênese ${ }^{4}$. Estudos in vivo e in vitro também demonstraram que a ingestão de ervamate por animais alimentados com dieta rica em lipídeos possui efeito antiobesidade, hipolipidêmico e hipoglicemiante ${ }^{5-7}$.

A tolerância à glicose diminuída está associada com o aumento da deposição de ácidos graxos provenientes da dieta no miocárdio, com a insuficiência precoce do ventrículo esquerdo e com maiores concentrações de triglicérides de jejum em obesos ${ }^{8,9}$. Conjuntamente com a obesidade, constitui-se como uma das principais bases fisiopatológicas para o desenvolvimento de doenças cardiovasculares e diabetes mellitus ${ }^{10}$.

Considerando-se que a obesidade e a resistência à insulina estão entre os principais fatores para o desenvolvimento de cardiopatias e diabetes mellitus, o presente estudo teve por objetivo avaliar o efeito do consumo de erva-mate sobre o ganho de peso e a glicemia de jejum em ratos alimentados com uma dieta hiperlipídica.

\section{MATERIAIS E MÉTODOS}

Para a composição do estudo foram utilizados 14 ratos (Rattus norvegicus, variedade Wistar), machos, recém-desmamados e com peso médio de 80,0 $\pm 5,0 \mathrm{~g}$, obtidos do Biotério da Fundação de Apoio à Universidade Federal de São Paulo.

Os animais foram divididos aleatoriamente em três grupos e mantidos em gaiolas coletivas (uma caixa por grupo), no Biotério do Centro de Ciências Biológicas e da Saúde da Universidade Presbiteriana Mackenzie, em um ciclo claro-escuro de 12 horas e com temperatura controlada de $23^{\circ} \mathrm{C}$

Inicialmente os animais passaram por um período de adaptação de 5 dias, em que foram alimentados com ração comercial para ratos (Nuvilab $\mathrm{CR}-1$ ) e água ad libitum. Após esse período, o grupo controle $(n=4)$ recebeu ração comercial padrão. $\bigcirc$ grupo hiperlipidêmico $(n=5)$ foi alimentado com ração contendo $80 \%$ de ração comercial e $20 \%$ de banha de porco. O grupo erva-mate $(n=5)$ recebeu ração que continha $80 \%$ de ração padrão e $20 \%$ de banha de porco e que foi homogeneizada com infusão de erva-mate $(600 \mathrm{~mL} / \mathrm{kg})$. Assim como no período de adaptação, o consumo da ração e da água foi ad libitum.

A infusão foi feita com erva-mate para chimarrão, nãotorrada. Foram pesados $200 \mathrm{~g}$ de erva-mate, que foram adicionados de $100 \mathrm{~mL}$ de água potável morna (40ํㅡ). Após a hidratação, que teve duração de 5 minutos, foram acrescentados $200 \mathrm{~mL}$ de água quente (85ํㅡ). Depois de 10 minutos, a infusão foi peneirada e reservada. À erva remanescente adicionou-se $300 \mathrm{~mL}$ de água quente. Ambas as infusões foram misturadas e utilizadas para a homogeneização da ração comercial padrão triturada com a banha de porco. Depois de homogeneizada, essa ração foi peletizada e secada em estuda ventilada a $60^{\circ} \mathrm{C}$, durante 48 horas. Após a secagem, a ração obtida foi embalada em sacos plásticos e mantida sob refrigeração até a sua utilização.

O estudo foi dividido em três períodos experimentais, sendo que o primeiro correspondeu ao $10^{\circ}$, o segundo ao $17^{\circ}$ e o terceiro ao $24^{\circ}$ dia. Em cada um desses períodos foram aferidos o peso (g) e o comprimento 


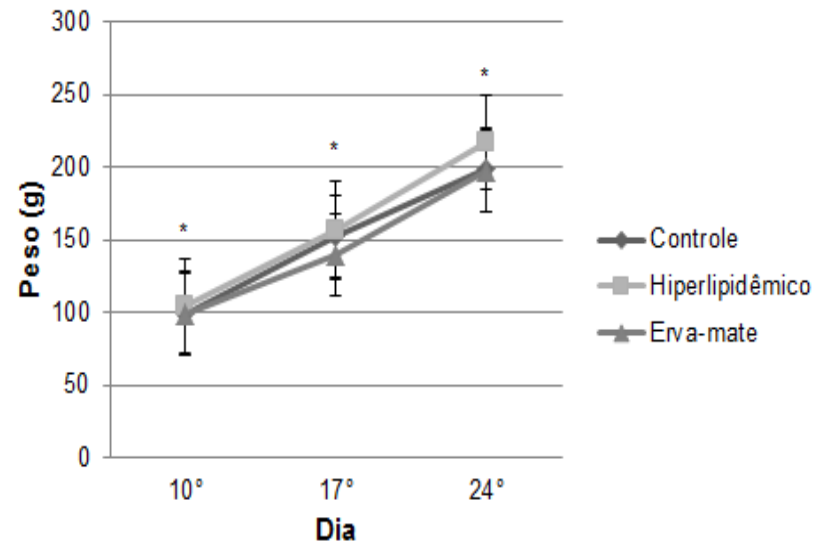

FIGURA 1 - Distribuição do peso dos animais dos diferentes grupos de acordo com cada período experimental. *Diferença estatística $(p<0,05)$ entre grupo erva-mate e hiperlipidêmico pelo teste de Mann-Whitney.

naso-anal (cm). O índice de massa corporal foi determinado pelo índice de Lee, que consiste na divisão da raiz cúbica do peso $(\mathrm{g})$ pelo comprimento naso-anal (cm) e a multiplicação do valor obtido por 1000. Ao final do estudo (24ํㅡㄹ dia) foi aferida a glicemia de jejum de 12 horas, com utilização de um monitor de glicemia AccuChek® (Roche).

A diferença dos dados das variáveis em estudo, de acordo com os grupos experimentais, foi avaliada pelo teste de Mann-Whitney, considerando-se como diferença estatisticamente significativa $p<0,05$. As análises estatísticas foram realizadas no software Assistat, versão 7.7 e os dados foram apresentados em mediana e amplitude interquartil.

O projeto foi submetido e aprovado pelo Comitê de Ética no Uso de Animais da Universidade Presbiteriana Mackenzie (CEUA), sob número 070/08/2010.

\section{RESULTADOS}

Nos três períodos experimentais verificou-se que o consumo da infusão de erva-mate na ração proporcionou menor ganho de peso nos animais desse grupo (figura 1), sendo que houve diferença estatística em relação ao grupo hiperlipidêmico ( $p=0,048 ; p=0,016$ e $\mathrm{p}=0,048$, respectivamente). Embora 0 grupo hiperlipidêmico tenha apresentado maior peso em relação ao grupo controle, não houve diferença estatisticamente significativa entre esses grupos ( $p=0,056 ; p=0,206$ e $p=0,206$, respectivamente), bem como não houve diferença entre o peso dos animais do

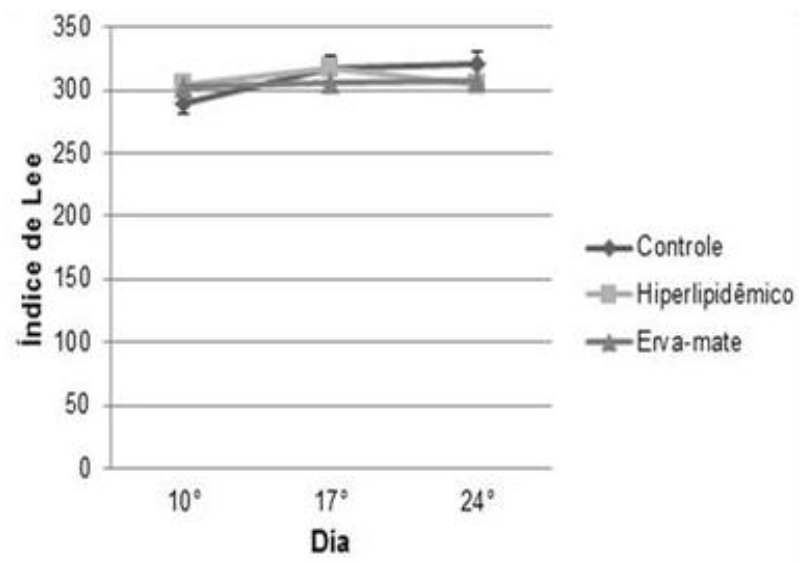

FIGURA 2 - Distribuição do índice de Lee médio dos animais dos diferentes grupos de acordo com cada período experimental.

grupo erva-mate e controle $(p=0,548 ; p=0,095$ e $\mathrm{p}=0,206)$.

Embora o ganho de peso dos animais do grupo hiperlipidêmico tenha sido maior, ao final do estudo esse grupo apresentou o menor índice de Lee (figura 2), contudo sem diferença estatística em relação aos demais grupos. Tal fato pode ser explicado pelo maior comprimento naso-anal desses ratos no $24^{\circ}$ dia de estudo, que apresentou mediana de 20,0 (19,0-20,0) $\mathrm{cm}$, contra $18,5(17,3-19,8) \mathrm{cm}$ do grupo controle e 19,0 $(18,5-19,5) \mathrm{cm}$ do grupo erva-mate, fazendo com que o quociente da divisão apresente-se menor do que nos demais grupos.

A glicemia de jejum foi menor no grupo que foi alimentado com dieta rica em lipídeos acrescida de infusão de erva-mate (figura 3). Embora a diferença não tenha sido significativa, percebe-se que houve essa tendência em relação ao grupo controle $(p=0,056)$ e ao grupo hiperlipidêmico $(p=0,075)$, sendo que o baixo número de animais e o tempo de estudo podem justificar a ausência de diferença significativa. Não houve diferença significativa na glicemia de jejum entre os grupos controle e hiperlipidêmico $(p=0,452)$.

\section{DISCUSSÃO}

No presente estudo, os animais alimentados com ração hiperlipídica acrescida de infusão de erva-mate apresentaram menor ganho de peso em relação ao grupo alimentado apenas com a dieta rica em lipídeos.

Tal efeito é corroborado por Pang et al. ${ }^{11}$, que 


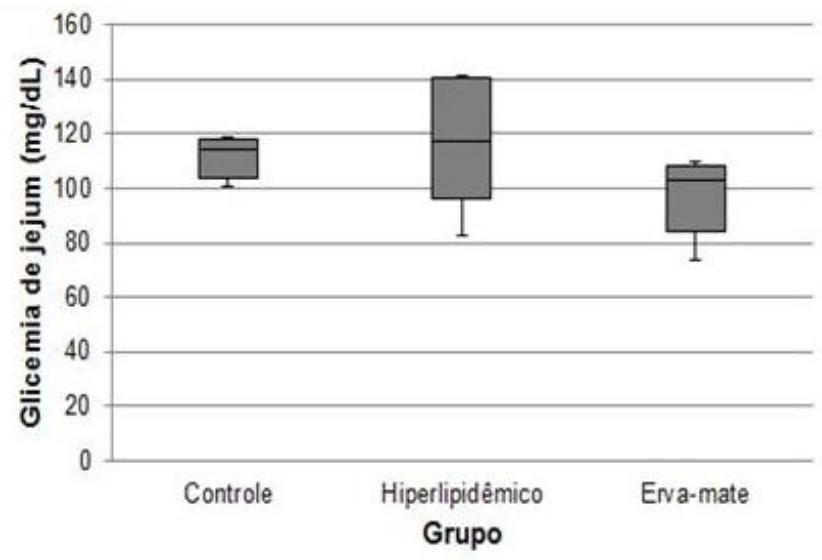

FIGURA 3 - Distribuição da glicemia de jejum dos animais dos diferentes grupos de acordo ao final do período experimental.

verificaram que o ganho de peso de ratos que consumiram ração hiperlipidêmica suplementada com extrato de erva-mate foi significativamente menor do que o de animais que receberam apenas ração rica em lipídeos. Hussein et al. ${ }^{12}$ demonstraram que a ingestão de ração hiperlipídica com extrato de erva-mate promoveu menor ganho de peso em relação aos animais que foram alimentados com essa dieta sem a adição da erva, mesmo efeito identificado por Kang et al. ${ }^{13}$. Hussein et al. ${ }^{14}$ constataram que a erva-mate promoveu diminuição do índice de Lee em ratos obesos e diabéticos.

Pode-se verificar que, independentemente da forma de administração, o consumo de erva-mate proporcionou menor ganho de peso em ratos alimentados com dieta rica em lipídeos, sendo a causa mais provável para tal fato o papel da erva na modulação de genes que regulam a adipogênese, atuando na via de sinalização WNT e resultando em repressão dos genes PPARy2 e CEBPa ${ }^{15}$, que regulam o processo adipogênico, sendo que o primeiro deles atua na diferenciação de pré-adipócitos em adipócitos imaturos e ambos, em conjunto, regulam a conversão de adipócitos imaturos em maduros ${ }^{16}$. Silva et al. ${ }^{17}$ identificaram que o consumo de erva-mate foi capaz de reduzir as gorduras abdominal e epididimal em ratos alimentados com uma dieta comercial padrão, bem como Lima et al. $^{18}$ que, além desses efeitos, identificaram que a ingestão da erva promoveu a redução do tecido adiposo subcutâneo e a área dos adipócitos em ratos obesos, o que pode justificar o menor ganho de peso nos animais que consumiram erva-mate no presente estudo.

Por sua vez, Pimentel et al. ${ }^{19}$ sugerem que o efeito anti-inflamatório da erva-mate pode estar relacionado a um menor ganho de peso em animais. Carmo et al. ${ }^{20}$ verificaram que o consumo de erva-mate em ratos alimentados com dieta hiperlipídica estimulou a redução da produção de adipocinas pro-inflamatórias, como IL$1 \alpha$, IL-6 e TNF- $\alpha$, que estão relacionadas com a obesidade e o processo aterosclerótico ${ }^{21}$.

Em relação à glicemia de jejum, no presente estudo os animais que ingeriram a infusão de erva-mate apresentaram menores valores em relação aos demais grupos, contudo sem diferença estatisticamente significativa. Przygodda et al. $^{22}$ identificaram que a glicemia de jejum foi menor ao final do experimento nos grupos que receberam dieta rica em lipídeos e açúcares e que foram suplementadas com extrato de erva-mate.

Arçari et al. $^{23}$ constataram que houve redução significativa da glicemia de animais alimentados com dieta hiperlipídica e extrato de erva-mate por gavagem em relação ao grupo que recebeu apenas dieta rica em lipídeos. Os autores comprovaram também que houve redução da resistência à insulina nesse grupo, verificada em teste de tolerância oral à glicose. Além desse efeito, o consumo de erva-mate também está associado na melhora da sinalização da insulina hepática, pela ação específica sobre a via PI3K-AKT ${ }^{24}$.

Contudo, em ratos com diabetes induzido pela aloxana, a ingestão de erva-mate não promoveu efeitos positivos na redução da glicemia, embora tenha reduzido significativamente a expressão gênica intestinal de SGLT1, tanto em animais diabéticos quanto não-diabéticos, sugerindo que os polifenóis presentes na erva podem interferir na absorção de glicose ${ }^{25}$.

Como fator limitante do presente estudo destaca-se o curto período de tempo em que o mesmo foi desenvolvido, podendo ser um indicativo da ausência de diferença significativa no peso e na glicemia de jejum entre o grupo controle e o hiperlipidêmico, como era esperada. Além disso, o tamanho amostral relativamente baixo também pode ser um fator que levou à ausência dessa diferença.

Conclui-se que o consumo da infusão de erva-mate na ração proporcionou menor ganho de peso em 
animais, embora não tenha apresentado efeito sobre o índice de Lee. A ingestão da erva também conferiu menores níveis séricos de glicose de jejum nesse grupo em relação aos demais, contudo sem apresentar diferença estatisticamente significativa.

\section{REFERÊNCIAS}

1. World Health Organization. Global Atlas on Cardiovascular Disease Prevention and Control. Geneva: WHO; 2011.

2. Xavier HT, Izar MC, Faria Neto JR, Assad MH, Rocha VZ, Sposito AC, Fonseca FA, Santos JE, Santos RD, Bertolami MC, Faludi AA, Martinez TLR, Diament J, Guimarães A, Forti NA, Moriguchi E, Chagas ACP, Coelho OR, Ramires JAF. V Diretriz Brasileira de Dislipidemias e Prevenção da Aterosclerose. Arq Bras Cardiol. 2013; 101(4):1-36.

3. Bastos DHM, Fornari AC, Queiroz YS, Torres EAFS. Bioactive compounds content of chimarrão infusions related to the moisture of yerba maté (Ilex paraguariensis) leaves. Braz Arch Biol Technol. 2006; 49(3):399-404.

4. Miranda DDC, Arçari DP, Pedrazzoli Jr J, Carvalho PO, Cerutti SM, Bastos DH, Ribeiro ML. Protective effects of mate tea (llex paraguariensis) on $\mathrm{H} 2 \mathrm{O} 2$-induced DNA damage and DNA repair in mice. Mutagenesis. 2008; 23(4):261-65.

5. Arçari DP, Bartchewsky Jr W, Santos TW, Oliveira KA, Funck A, Pedrazzoli Jr J, Souza MF, Saad MJ, Bastos DH, Gambero A, Carvalho PO, Ribeiro ML. Antiobesity effects of yerba maté extract (llex paraguariensis) in high-fat dietinduced obese mice. Obesity. 2009;17(12):2127-33.

6. Martins F, Noso TM, Porto VB, Curiel A, Gambero A, Bastos DH, Ribeiro ML, Carvalho PO. Maté tea inhibits in vitro pancreatic lipase activity and has hypolipidemic effect on high-fat diet-induced obese mice. Obesity. 2010;18(1):42-7.

7. Pereira DF, Kappel VD, Cazarolli LH, Boligon AA, Athayde ML, Guesser SM, Silva EL, Silva FR. Influence of the traditional Brazilian drink llex paraguariensis tea on glucose homeostasis. Phytomedicine. 2012; 19(10):86877.

8. Labbé SM, Grenier-Larouche T, Noll C, Phoenix S, Guérin B, Turcotte EE, Carpentier AC. Increased myocardial uptake of dietary fatty acids linked to cardiac dysfunction in glucose-intolerant humans. Diabetes. 2012; 61(11):270110.

9. Berings M, Wehlou C, Verrijken A, Deschepper E, Mertens I, Kaufman JM, Van Gaal LF, Ouwens DM, Ruige JB. Glucose intolerance and the amount of visceral adipose tissue contribute to an increase in circulating triglyceride concentrations in Caucasian obese females. PLoS One. 2012; 7(9):e45145.

10. Lauria MW, Dias INB, Soares MMS, Cordeiro GV, Barbosa VE, Ramos AV. Análise de fatores que se associam a alterações no teste de tolerância oral à glicose, independentemente dos valores de glicemia de jejum. Arq Bras Endocrinol Metab. 2011; 55(9):708-13.

11. Pang J, Choi $\mathrm{Y}$, Park T. Ilex paraguariensis extract ameliorates obesity induced by high-fat diet: potential role of AMPK in the visceral adipose tissue. Arch Biochem Biophys. 2008;476(2):178-85.

12. Hussein GME, Matsuda $H$, Nakamura $S$, Hamao $M$, Akiyama T, Tamura K, Yoshicawa M. Mate tea (llex paraguariensis) promotes satiety and body weight lowering in mice: involvement of glucagon-like peptide-1. Biol Pharm Bull. 2011;34(12):1849-55.

13. Kang YR, Lee HY, Kim JH, Moon DI, Seo MY, Park SH,
Choi KH, Kim CR, Kim SH, Oh JH, Cho SW, Kim SY, Kim MG, Chae SW, Kim O, Oh HG. Anti-obesity and antidiabetic effects of yerba mate (llex paraguariensis) in C57BL/6J mice fed a high-fat diet. Lab Anim Res. 2012; 28(1):23-9.

14. Hussein GME, Matsuda $H$, Nakamura $S$, Akiyama $T$, Tamura K, Yoshikawa M. Protective and ameliorative effects of maté (llex paraguariensis) on metabolic syndrome in TSOD mice. Phytomedicine. 2011; 19(1):8897.

15. Arçari DP, Santos JC, Gambero A, Ribeiro ML. The in vitro and in vivo effects of yerba mate (llex paraguariensis) extract on adipogenesis. Food Chem. 2013; 141(2):80915.

16. Queiroz JCF, Alonso-Vale MIC, Curi R, Lima FB. Controle da adipogênese por ácidos graxos. Arq Bras Endocrinol Metab. 2009; 53(5):582-94.

17. Silva RD, Bueno ALS, Gallon CW, Gomes LF, Kaiser S, Pavei C, Ortega GG, Kusharski LC, Jahn MP. The effect of aqueous extract of gross and commercial yerba mate (llex paraguariensis) on intra-abdominal and epididymal fat and glucose levels in male Wistar rats. Fitoterapia. 2011;82(6):818-26

18. Lima NS, Franco JG, Peixoto-Silva N, Maia LA, Kaezer A Felzenszwalb I, Oliveira E, Moura EG, Lisboa PC. Ilex paraguariensis (yerba mate) improves endocrine and metabolic disorders in obese rats primed by early weaning. Eur J Nutr. 2014;53(1):73-82.

19. Pimentel GD, Lira FS, Rosa JC, Caris AV, Pinheiro F, Ribeiro EB, Nascimento CMO, Oyama LM. Yerba mate extract (Ilex paraguariensis) attenuates both central and peripheral inflammatory effects of diet-induced obesity in rats. J Nutr Biochem. 2013;24(5):809-18.

20. Carmo LS, Rogero MM, Cortez M, Yamada M, Jacob PS, Bastos DH, Borelli P, Fock RA. The effects of yerba maté (Ilex paraguariensis) consumption on IL-1, IL-6, TNF- $\alpha$ and IL-10 production by bone marrow cells in wistar rats fed a high-fat diet. Int J Vitam Nutr Res. 2013;83(1):26-35.

21. Ikeoka D, Mader JK, Pieber TR. Adipose tissue, inflammation and cardiovascular disease. Rev Assoc Med Bras. 2010; 56(1):116-21.

22. Przygodda F, Martins ZN, Castaldelli APA, Minella TV, Vieira LP, Cantelli K, Fronza J, Padoin MJ. Effect of ervamate (llex paraguariensis A. St.-Hil., Aquifoliaceae) on serum cholesterol, triacylglycerides and glucose in Wistar rats fed a supplemented with fat and sugar. Rev Bras Farmacogn. 2010; 20(6):956-61.

23. Arçari DP, Bartchewsky Jr W, Santos TW, Oliveira KA Oliveira CC, Gotardo EM, Pedrazzoli Jr J, Gambero A, Ferraz LF, Carvalho PO, Ribeiro ML. Anti-inflammatory effects of yerba maté (llex paraguariensis) ameliorate insulin resistance in mice with high fat diet-induced obesity. Mol Cell Endocrinol. 2011;335(2):110-5.

24. Arçari DP, Santos JC, Gambero A, Ferraz LFC, Ribeiro ML. Modulatory effects of yerba maté (Ilex paraguariensis) on the PI3K-AKT signaling pathway. Mol Nutr Food Res. 2013;57(10):1882-5.

25. Oliveira DM, Freitas HS, Souza MF, Arçari DP, Ribeiro ML, Carvalho PO, Bastos DH. Yerba maté (llex paraguariensis) aqueous extract decreases intestinal SGLT1 gene expression but does not affect other biochemical parameters in alloxan-diabetic Wistar rats. J Agric Food Chem. 2008;56(22):10527-32.

\section{Endereço para correspondência}

Alisson Diego Machado

Rua Marisa $\mathrm{n}$ - 121

Barueri/SP - CEP 06436-190

Telefone: +55 1141945355 / 11980541963

E-mail: alissondiegomachado@hotmail.com 